\title{
A Curriculum for Developing Serious Games for Children with Autism: A Success Story
}

\author{
Vedad Hulusic \\ LTCI, Télécom ParisTech \\ Université Paris-Saclay \\ Paris, France \\ Email: vedad.hulusic@telecom-paristech.fr
}

\author{
Nirvana Pistoljevic \\ Teachers College \\ Columbia University \\ New York NY 10027, USA \\ Email:np2127@tc.columbia.edu
}

\begin{abstract}
Autism Spectrum Disorder (ASD) is a neurodevelopmental disorder, detectable early in development and characterized by the lack of socialization, development of language and patterns of rigid, repetitive, auto-stimulating behaviors that interfere with overall functioning of a person. Due to reduced level of attention and different style of learning, teaching children with ASD requires a particular set of tools and methods. Studies have shown that computer-based intervention, typically in form of serious games, can be effectively utilized for developing various skills, allowing children with disabilities both learning with teachers and practicing on their own time, when the taught concepts are presented in a fun, informal, and engaging way. Nonetheless, there is a limited amount of appropriately designed serious games for children with ASD, especially in less spread languages native to the children. In this paper we present a complete curriculum for final year Computer Science (CS) undergraduate students, aimed at developing web-based serious games for teaching children with and without autism basic concepts. In addition, we present multiple outcomes of such course taught by the authors, computer scientist and a psychologist and a special educator. We believe that inclusion of such curriculum in CS undergraduate programs could benefit both the students, children with ASD, teachers of both groups and the community in general.
\end{abstract}

\section{INTRODUCTION AND BACKGROUND WORK}

Autism spectrum disorder (ASD) is a group of complex neurodevelopmental disorders characterized by the difficulties in social interaction and communication and distinctive patterns of repetitive, auto-stimulating and rigid behaviors that interfere with everyday functioning of an individual [1]. Children with ASD process stimulation differently and thus learn in a different way, so the design of education curricula for such learners has been a challenge. In addition, we know that children with ASD spend significantly more time using screen-based media then any other free-time activity [2], [3]. Mazurek and Wenstrup [3] analyzed TV, video game, and social media use in children with ASD compared to their typically developing siblings and found that children with ASD spent approximately $62 \%$ more time watching TV and playing video games then all other free-time activities like reading or playing with friends. This is consistent with the diagnosis of ASD, being that the social and communication skills are impaired. Given such strong evidence for preference and enjoyment in playing video games among children with
ASD [4], clinicians and educators should maximize this and use screen-based media to motivate young learners with ASD.

\section{A. Teaching machines and the learn unit}

In order to introduce computer scientists with proper learning theories, we based our game design on the work by Skinner, who argued for the benefits of teaching machines decades ago, identifying them as capital equipment used by educators to save time and labor, permitting a learner to play an active role in the learning process [5]. He stated numerous benefits of teaching machines, like student led and paced instruction, machine being a teacher with infinite patience providing individualization of learning, its adaptability for students with special needs, continuous and immediate feedback they provide to each learner, and therefore being a highly motivating educator.

As for the principles of the learning theory, we put emphasis on the fundamental measure of teaching and learning, a learn unit [6], which consists of an exchange of antecedentsbehaviors-consequences between a teacher (device) and a student, and it has been utilized in designing computer based instruction [5], [7], [8]. One part of the curriculum for students was learning about the learn unit and rules of the appropriate design that induces learning. All games designed were based on the learn unit, an interlocking three-term-contingency where a device presents a visual and auditory antecedent and delivers feedback to the students behavior emitted to the task presented. as a part of the learn unit, consequence brings about learning [5], [6]. In our curriculum, emphasis was placed on the corrective feedback following each incorrect response and providing positive reinforcement following each correct response, in addition to the score keeping.

\section{B. Educational and health serious games}

The concept of game-based learning and using serious games in education has been present for decades [9], [10]. Serious games, with a main goal of learning and therefore improving real life outcomes, focus on skills acquisition and generalization beyond the game itself. A systematic and extensive review of serious games, with an emphasis on the positive aspects of gaming on learning and skill enhancement, has been presented by Connolly et al. [11]. In their work they showed 
that playing computer (serious) games can have multiple positive cognitive, behavioral and motivational effects.

Besides the educational serious games, this medium has been used for physical, mental, and social well-being treatment [12]. Recently, there has been lots of interest using game- and computer-based interventions to teach new skills and behaviors to children with ASD [13], [14], [8], [15], [16]. The main objective of these games is to teach children various basic developmental skills. An extensive review of such games, classifying them according to technology platform, computer graphics (2D vs 3D), gaming aspect and user interaction can be found in work by Zakari et al. [17].

\section{Curricula development}

Classical approach to teaching uses isolated curricula is slightly shifting towards the integrated curriculum, which connects different areas of study by emphasizing common concepts [18]. In addition, one of the efforts of the Games and Learning Alliance (GaLA), an EC-funded Network of Excellence on SGs, is to integrate serious games into curricula [19]. Nonetheless, to the best of authors' knowledge, there is no available curriculum for Computer Science (CS) students designed for developing serious games, and more specifically, serious games for children with disabilities.

Main contributions of this work are multifold. Firstly, we propose a complete curriculum for final year undergraduate course for CS studies. Secondly, besides the intended learning outcomes, practical and transferable skills, a set of 15 serious games for teaching children with and without autism the basic concepts, developed based on educational theories and decades of research on science of learning and human behavior, were deployed and are used in centers for special education around the country. Finally, both the curriculum and the games produced within the course, have a significant socio-economic impact, as such simple self-instructed basic educational software could provide painless introduction of the computer-directed learning and technology as part of the educational and pedagogical process in all schools.

\section{THE CURRICULUM AND TIME PLAN}

In this section, the curriculum for a final (fourth) year undergraduate course, Independent Project Study, at the CS department is described. The course has been taught for the first time by the instructor, and therefore, the curriculum has been entirely developed with a specific practical intent, while following the overall intended learning outcomes. The main aim of the course was to familiarize CS students with some specific, advanced concepts of web development through individual projects.

\section{A. Course outline}

The course was designed as a Level 6 within the Framework for Higher Education Qualifications (FHEQ), and carried 6 ECTS $^{1}$ credits. The course duration was 15 weeks, with two hours of lectures and two hours of tutorials per week. The

\footnotetext{
${ }^{1}$ European Credit Transfer and Accumulation System
}

assessment was done through a mid-term test, project work and a final exam, with weights of $20 \%, 30 \%$ and $50 \%$ respectively.

During the lectures, in the first four weeks the students were introduced to the following topics: serious games, learn unit, educational game design, HTML5 - a revision, as they were taught this in the second year of their studies, CSS3, JQuery and JQueryUI; and to the project task, game descriptions and timeline. They were also provided with a relevant literature from the educational serious games domain. From week 4 to week 12 , they had weekly revisions and biweekly deadlines, where the game elements were introduced gradually using an adjusted spiral approach [20], and individual progress was discussed. During week 12, the beta versions of the games were tested with children with autism in a center for special education, allowing the students to obtain direct feedback from the professional workers in the center, and to observe and record user behavior, in order to see if the game was appropriately sequenced for learning. In week 13, they were asked to submit the final versions of their games with implemented corrections. In the last two weeks they had to present their work and demonstrate the games.

During the tutorial sessions, they did several exercises with a teaching assistant (TA), for practicing the related concepts using HTML, CSS, JQuery and JQueryUI. After that, they stared working on their individual projects, while advanced topics were explained on simple examples by the TA.

\section{B. Game descriptions and scenarios}

The descriptions for all 15 games were developed jointly by an expert from the special education with behavioral science background, and the course instructor. All description had several elements: name, stimuli, and main selection. Depending on a game, the main selection could contain the field size (number of test/target stimuli), type of antecedent (vocal, visual, both), type of stimuli or grouping (identical versus non-identical stimuli), and the order of stimuli (ascending, descending). In addition, there was a textual description of the game scenario, and a low-level prototype, i.e. a symbolic representation of the screen elements, see Fig. 1. Each game had one of the following types of stimuli: numbers, letters, special characters, colors, words, pictures or splodges, and was used for teaching one of the concepts: sameness, difference, sound matching, size, sorting/categorizing, ordering, word construction, sentence construction and pointing out/selecting. All games had several common required features, used mainly for guiding the design and development process.
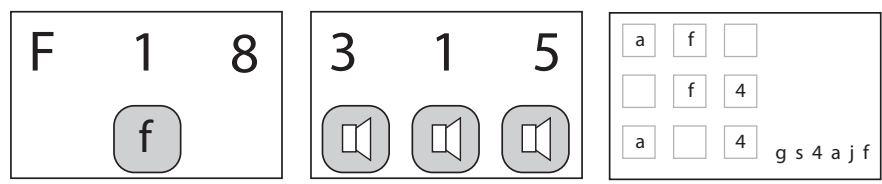

Fig. 1: Symbolic representations of the screen elements for three games: One that goes together with (left), One that matches the sound it makes (middle), Find the pattern (right). 
TABLE I: Project phases and the work plan over 15 weeks. Second column represents the percentage of the final course grade $-30 \%$ in total.

\begin{tabular}{|c|c|c|}
\hline $\begin{array}{c}\text { Week/ } \\
\text { deadline }\end{array}$ & $\begin{array}{c}\text { Grade } \\
\text { weighting }(\%)\end{array}$ & Description \\
\hline 4 & 5 & $\begin{array}{l}\text { Students are expected to submit visual design for the game in vector format and a description of work. It should contain } \\
\text { the following elements: background, test stimuli, score, consequence - feedback for correct response and a correction for } \\
\text { an incorrect response, and final screen with the score and "Back to main menu" / "Play again" buttons. }\end{array}$ \\
\hline 6 & 3 & $\begin{array}{l}\text { Students are expected to submit a HTML/CSS implementation of the proposed design for the game, containing all the } \\
\text { elements as in the design, e.g. background, test stimuli, score, consequence and the final screen with work description. }\end{array}$ \\
\hline 8 & 5 & $\begin{array}{l}\text { Students are expected to submit a web page with all required components to implement main functionality, e.g. a user } \\
\text { can test the game on } 2 \text { trials (i.e. two colors, two numbers or two letters) and a description of work. All the effects } \\
\text { required for this functionality should be implemented, including: show background, show stimuli, select/drag\&drop/ } \\
\text { arrange/order the stimuli, show consequence, and go to the next trial. }\end{array}$ \\
\hline 10 & 3 & $\begin{array}{l}\text { Students are expected to submit the same content as in the previous iteration, but for all } 10 \text { trials ( } 10 \text { randomly ordered } \\
\text { stimuli) and a description of work. }\end{array}$ \\
\hline 12 & 5 & Students are expected to submit the full game with the main menu and a description of work. \\
\hline 12 & - & GAME TESTING \\
\hline 13 & 2 & Students are expected to submit their games with final corrections implemented and a final document. \\
\hline 14 & 4 & $\begin{array}{l}\text { Project description document - needs to contain at least } 2000 \text { words, and describe the whole application and the work } \\
\text { undertaken in the design and development process. }\end{array}$ \\
\hline $14 / 15$ & 3 & Students are expected to present their projects within 10 minutes. \\
\hline
\end{tabular}

\section{Project phases and the work plan}

In the first weeks of the course, the students were presented with the work plan, as summarized in Table I. It consisted of several main phases, that were biweekly evaluated. The first phase was the visual design of the game. In the second phase, they were asked to implement a static version of the design using HTML and CSS. In the next phase, the students had to implement main functionality of the game (a subset of functionalities) and the required effects. In the following phase, they were requested to implement the remaining functionalities, and finally to submit the full game with the main menu. In all the phases, they had to write and submit the description of work, explaining the work they have conducted. The games were then tested on children with autism in the center for special education, where comments from the instructors and observations were recorded and used for final corrections. Finally, the students submitted the project description document and presented they work in the class.

\section{Course assessment}

The development of curricula for each course at the University SSST had to follow prescribed guidelines. One of the criteria for the assessment must comprise midterm and final exam. The other one is that the final exams are weighted $50 \%$ of the final grade. The rest was divided into the midterm exam (20\%) and project work (30\%). Project grading is further presented in Table I.

Both, the final and midterm exams were done practically, on the PCs in the course laboratory. They both consisted of one single task - to develop a described web application using HTML, CSS, JQuery and JQueryUI. The students were provided with the screenshots of all the pages of the application and detailed instructions on how the application behaves and looks like, i.e. rules, dimensions, distances and color codes. The exams were designed so that they reflect the required knowledge for completing the student projects.

\section{ThE OUTCOMES AND EVALUATION RESULTS}

The outcomes of the course were multifold. These could be observed in two separate categories: the knowledge and skills acquired by the university students, and the set of serious games for teaching children with ASD basic concepts.

The main practical skills the students have developed are: using HTML, CSS, JQuery and JQueryUI in practice; ability to develop educational serious games for the web; ability to use specialized resources for computer science research. In addition, they developed several transferable skills, such as ability to solve problems, attention to details, ability to work creatively, capacity to deliver work to a given brief, format and deadline, and self management skills.

As the tangible output, there were 15 fully-functional serious games for children with and without autism, as a result of the student work within the course, see Figure 2 for screenshots of three games. All the games were tested with children with autism for potential flaws and shortcomings. Minor corrections were made, based on students' and professional workers' observations. The game effectiveness on learning process will be further tested in the future.

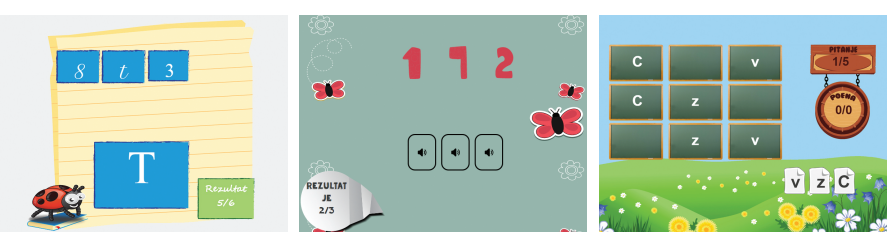

Fig. 2: Final design for the three games presented in Fig. 1.

Overall coursework grades achieved at the course ranged from 41 to 97, with the average of 77 (out of 100). One student did not show up for the final exam, and thus received 0 points. The failing student passed the remedial exam. During the annual module review, it was reported that the intended learning outcomes were achieved as planned and that the methods of assessment for evaluating achievement of intended 
learning outcomes were suitable. In addition, the student feedback about both the course and the teacher was very positive. Finally, it was reported that the students showed significant level of enthusiasm while working on their projects and that they were happy about the fact that their applications will be used in a real-life environment.

\section{CONCLUSION}

It is apparent that technology has become a part of our everyday leisure life. However, the education system seems to be lagging behind in using all its potential appropriately. This is especially apparent for children with disabilities, as too many not evidence-based new technologies offering miraculous not proven results are everywhere [16], [21]. Therefore, there is a need for clearer guidelines on design of (educational) serious games and maybe better curricula for game developers, that will encompass all the evidence-based components of what proper educational interactive game should have. With this paper, we have attempted to discuss development and testing of the curricula for computer science students and serious game developers through their final product, educational games for children with ASD. We wanted to capitalize on the science of teaching, learning theory, serious game design and computer science advancements when trying to create a sequence for students to follow in order to design their own games for learning. At the same time, this was compliant with the course's overall objectives, i.e. teaching advanced web concepts and technologies through individual projects. To the best of out knowledge, there is no such curricula either developed or tested.

In this paper, a complete curriculum for an undergraduate CS course, focusing on the development of web-based educational video games, was proposed. With the implementation of such curriculum, we were able to design and test a set of 15 serious games for teaching preschool and school children with special needs the basic concepts. Furthermore, we have demonstrated that simple self-instructed basic educational software could provide introduction of the computer-assisted learning and technology as part of the learning process in all schools. Because of that, both the curriculum and the games produced within the course, have a significant socio-economic impact, as especially in the low- and mid-income countries like Bosnia and Herzegovina, where funding for advancement in education is almost nonexistent. Games developed by students for children promote the computer-based learning and incorporating technology in the classroom with little or no funding and professional development and investment by the teachers and education sector. Furthermore, games can be played at home, providing an alternative for children with disabilities, an extension to the time spent at school. This curriculum indirectly will provide children with and without disabilities with appropriate educational software, to build up their early cognitive abilities and school readiness skills. Although it was specifically designed for this purpose and web technologies, the curriculum can be adapted or extended for similar projects and technologies. We believe that it can serve as a solid base and framework for other similar, project-based undergraduate CS curricula. The fact that the project outcome was tangible and applicative, with an extraordinary cause, was both remarkably appreciated by and greatly motivating to the students.

\section{ACKNOWLEDGMENT}

The practical work on the serious games developed within the course is a supervised student work. The preliminary testing was done at EDUS (www.edusbih.org) with children with ASD. The authors would like to thank the children and the educators from EDUS for their valuable feedback.

\section{REFERENCES}

[1] A. P. Association et al., Diagnostic and statistical manual of mental disorders (DSM-5®). American Psychiatric Pub, 2013.

[2] H. C. Shane and P. D. Albert, "Electronic screen media for persons with autism spectrum disorders: Results of a survey," Journal of autism and developmental disorders, vol. 38, no. 8, pp. 1499-1508, 2008.

[3] M. O. Mazurek and C. Wenstrup, "Television, video game and social media use among children with asd and typically developing siblings," Journal of autism and developmental disorders, vol. 43, no. 6, pp. 12581271, 2013.

[4] G. I. Orsmond and H.-Y. Kuo, "The daily lives of adolescents with an autism spectrum disorder: discretionary time use and activity partners," Autism, vol. 15, no. 5, pp. 579-599, 2011.

[5] B. F. Skinner, "Teaching machines." Science, 1958.

[6] R. D. Greer and S. H. McDonough, "Is the learn unit a fundamental measure of pedagogy?" The Behavior Analyst, vol. 22, no. 1, p. 5, 1999.

[7] H. H. Emurian, "Programmed instruction for teaching java: Consideration of learn unit frequency and rule-test performance." The Behavior Analyst Today, vol. 8, no. 1, p. 70, 2007.

[8] V. Hulusic and N. Pistoljevic, "Teaching children with and without disabilities school readiness skills," in WSEAS European Computing Conference, 2013, pp. 316-323.

[9] K. Squire, "Video games in education," in International journal of intelligent simulations and gaming. Citeseer, 2003.

[10] S. I. De Freitas, "Using games and simulations for supporting learning," Learning, media and technology, vol. 31, no. 4, pp. 343-358, 2006.

[11] T. M. Connolly, E. A. Boyle, E. MacArthur, T. Hainey, and J. M. Boyle, "A systematic literature review of empirical evidence on computer games and serious games," Computers \& Education, vol. 59, no. 2, pp. 661$686,2012$.

[12] V. Wattanasoontorn, I. Boada, R. García, and M. Sbert, "Serious games for health," Entertainment Computing, vol. 4, no. 4, pp. 231-247, 2013.

[13] O. Grynszpan, P. L. Weiss, F. Perez-Diaz, and E. Gal, "Innovative technology-based interventions for autism spectrum disorders: a metaanalysis," Autism, vol. 18, no. 4, pp. 346-361, 2014.

[14] V. Hulusic and N. Pistoljevic, "“lefca": Learning framework for children with autism," Procedia Computer Science, vol. 15, pp. 4-16, 2012.

[15] — Read, Play and Learn: An Interactive E-book for Children with Autism. Cham: Springer International Publishing, 2016, pp. 255-265.

[16] E. M. Whyte, J. M. Smyth, and K. S. Scherf, "Designing serious game interventions for individuals with autism," Journal of autism and developmental disorders, vol. 45, no. 12, pp. 3820-3831, 2015.

[17] H. M. Zakari, M. Ma, and D. Simmons, "A review of serious games for children with autism spectrum disorders (asd)," in International Conference on Serious Games Development and Applications. Springer, 2014, pp. 93-106.

[18] S. M. Drake, Creating Integrated Curriculum: Proven Ways To Increase Student Learning. ERIC, 1998.

[19] M.-M. Popescu, J. Earp, and P. M. Ger, "Aspects of serious games curriculum integrationa two-fold approach," Internet Learning, vol. 2, no. 1 , p. 7, 2015.

[20] J. S. Bruner, "The process of education. 1960," Cambridge, MA: Harvard UP, 1977.

[21] V. Knight, B. R. McKissick, and A. Saunders, "A review of technologybased interventions to teach academic skills to students with autism spectrum disorder," Journal of autism and developmental disorders, vol. 43, no. 11, pp. 2628-2648, 2013. 